\title{
Development of pioglitazone hydrochloride lipospheres by melt dispersion technique: Optimization and evaluation
}

\author{
Umesh M Bhosale, Upendra C Galgatte*, Pravin D Chaudhari \\ Department of Pharmaceutics, P.E. Society's Modern College of Pharmacy, Nigdi, Pune 411044, India.
}

\begin{tabular}{|c|c|}
\hline ARTICLE INFO & ABSTRACT \\
\hline $\begin{array}{l}\text { Article history: } \\
\text { Received on: } 10 / 08 / 2015 \\
\text { Revised on: } 02 / 09 / 2015 \\
\text { Accepted on: } 12 / 12 / 2015 \\
\text { Available online: } 26 / 01 / 2016\end{array}$ & $\begin{array}{l}\text { The objective of the present study was to develop and evaluate pioglitazone hydrochloride loaded lipospheres for } \\
\text { treatment of diabetes. Pioglitazone hydrochloride lipospheres were formulated by using melt dispersion } \\
\text { (homogenization) technique using compritol }{ }^{\circledR} 888 \text { ATO as lipid matrix and Phospholipon } 90 \mathrm{G} \text { (P 90G), PVA, } \\
\text { Poloxamer } 188 \text { as surfactants. Formulation was optimized by using } 3^{2} \text { full factorial design where entrapment } \\
\text { efficiency and particle size were dependent variables and lipid and surfactant concentration were independent }\end{array}$ \\
\hline $\begin{array}{l}\text { Key words: } \\
\text { Pioglitazone hydrochloride; } \\
\text { lipospheres; compritol }{ }^{\circledR} 888 \\
\text { ATO; melt dispersion } \\
\text { technique; factorial design. }\end{array}$ & $\begin{array}{l}\text { efficiency, } 94.63 \pm 2.10 \% \text { drug content and particle size was found to be } 23.74 \pm 0.35 \mu \mathrm{m} \text { with spherical shaped } \\
\text { free flowing particles. In vitro release was carried out using dissolution apparatus in } 0.1 \mathrm{~N} \mathrm{HCl} \text { and optimized } \\
\text { formulation shows } 96.06 \pm 0.54 \% \text { drug release within } 8 \text { hrs. which follows quasi-fickian type of transport and } \\
\text { was characterized by the Korsmeyer- Peppas model. Formulation was stable at } 5{ }^{\circ} \mathrm{C} \pm 3{ }^{\circ} \mathrm{C} \text { for two months. } \\
\text { Developed liposphere formulation was able to sustain the drug release and entrap the pioglitazone hydrochloride } \\
\text { drug at high level. }\end{array}$ \\
\hline
\end{tabular}

\section{INTRODUCTION}

Diabetes mellitus (DM) is a chronic metabolic disorder characterized by hyperglycemia caused by defective insulin secretion, resistance to insulin action, or a combination of both. Adjustments of lipid and protein metabolism also are important manifestations of these defects in insulin secretion or action. Most patients with diabetes mellitus have either type 1 diabetes (which is immune-mediated or idiopathic) or type 2 diabetes (with a complex pathophysiology that combines progressive insulin resistance and beta-cell failure and has a heritable basis). Type 2 diabetes mellitus (T2DM) is a progressive disease characterized by hyperglycaemia, due to inadequate control of levels of blood glucose by the pancreatic hormone insulin and/or abnormal resistance to insulin. The principle aim of liposphere diabetes treatment is to control blood glucose levels, in order to prevent mortality and long-term complications (USFDA Guidance for industry, 2008). Diabetes is fast gaining the status

\footnotetext{
* Corresponding Author

Email: ucgpharm@rediffmail.com
}

of a potential epidemic in India with more than 62 million diabetic individuals currently diagnosed with the disease (ICMR Guidelines, 2005).

Pioglitazone hydrochloride, an oral hypoglycemic agent, is one of the most commonly prescribed drug for the treatment of patients with diabetes mellitus type II. Pioglitazone hydrochloride is water insoluble and belongs to BCS class II, having short halflife 3-7 hrs. Pioglitazone hydrochloride is to be administered in 2 to 3 doses of 15 to $45 \mathrm{mg}$ per day hence selected as drug for formulation of lipospheres. The goals of antidiabetic therapy are to prevent imminent mortality and alleviating symptoms (USFDA Guidance for industry, 2008; Indian Pharmacopoeia, 2010). Lipospheres (LS) are being developed as substitutes for "polymer based delivery systems" due to the increasing problems related to toxicity of monomers after intracellular processing of polymers and attractive advantages offered by lipids as carriers (Patel et al., 2011). Lipospheres are aqueous micro dispersion of solid water insoluble spherical micro particles of particle size between 0.02 to $100 \mu \mathrm{m}$ in diameter which is composed of a solid hydrophobic lipid core (triglycerides), stabilized by a layer of phospholipid molecules embedded on their surface. 
The internal core contains the bioactive compound dissolved or dispersed in the solid fat matrix (Chime and Onyishi, 2013). The lipospheres are suitable for oral, parenteral and topical drug delivery of bioactive compounds. Various liposphere formulations have been used for the controlled delivery of different types of drugs including anti-inflammatory compounds, local anesthetics, antibiotics and anticancer agents, as well as carriers of vaccines and adjuvants (Chime et al., 2012). It has various advantages over other drug delivery systems like high dispersability in an aqueous medium and eases of preparation and scale up. High entrapment of hydrophobic drugs, controlled particle size and low cost of ingredients (Soumya et al., 2012).

Lipospheres exhibit enhanced physical stability due to avoidance of coalescence and extended release of entrapped drug after a single injection. Reduced mobility of entrapped drug molecules responsible for reduction of drug leakage (Lakshmi and Saroja, 2012).

There are several methods for formulation of lipospheres but melt dispersion technique was best suitable technique because this technique have many advantages over other techniques such as less number of ingredients are required, high entrapment of drug, ease of preparation. Several other techniques, such as solvent evaporation, hot and cold homogenization, solvent extraction, sonication method, multiple microemulsions and rotoevaporation technique have been used for the formulation of lipospheres (Satheeshbabu and Gowthamrajan, 2011).

\section{MATERIALS AND METHOD}

\section{Materials}

Pioglitazone hydrochloride was a generous gift sample from Sava Healthcare Ltd., India. Compritol ${ }^{\circledR} 888$ ATO was purchased from Gattefosse India Pvt. Ltd, Mumbai, India. Phospholipon 90G (P 90G) was purchased from Lipoid, Germany. Polyvinyl alcohol was purchased from Loba chemie Pvt. Ltd, Mumbai, India and Poloxamer 188 was purchased from BASF, Mumbai, India. All the other reagents and chemicals used were of analytical grade.

\section{Preparation Method}

Pioglitazone hydrochloride lipospheres were prepared by melt dispersion (Homogenization) technique. The lipid phase

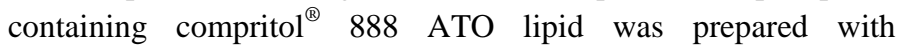
pioglitazone hydrochloride. The lipid phase was melted at $70^{\circ} \mathrm{C}$ and then pioglitazone hydrochloride was added to lipid phase. Aqueous phase was prepared separately by adding surfactants $\mathrm{P}$ 90G, PVA and poloxamer 188 in hot distilled water above the melting temperature of lipid phase at $80{ }^{\circ} \mathrm{C}$ and dissolved. Lipid phase was then emulsified by adding hot external aqueous phase maintained at $80{ }^{\circ} \mathrm{C}$ containing suitable surfactant. The emulsion was homogenized by using Ultra Turrax high speed homogeniser $\left(\right.$ IKA $^{\circledR}$ T-25 Digital Ultra Turrax Homogeniser) and maintained at $80{ }^{\circ} \mathrm{C}$ during homogenization. Then, the emulsion formulation was rapidly cooled to about $10{ }^{\circ} \mathrm{C}$ by immersing the formulation into an ice bath and continuing the agitation to yield uniform dispersion of lipospheres. The obtained lipospheres was then washed with water and isolated by filtration through a whatman filter paper 42 (Momoh and Esimone, 2012).

\section{UV spectrum analysis of pioglitazone hydrochloride}

Pioglitazone hydrochloride was accurately weighed (10 $\mathrm{mg}$ ) and transferred to a separate $10 \mathrm{ml}$ volumetric flask and dissolved by using suitable solvent (methanol, $0.1 \mathrm{~N} \mathrm{HCl}$ ) and diluted up to the mark by using suitable solvent to obtain a separate standard stock solutions having concentration of pioglitazone hydrochloride $(1000 \mu \mathrm{g} / \mathrm{ml})$.

The working standard solution containing pioglitazone hydrochloride at concentrations of 100 and $10 \mu \mathrm{g} / \mathrm{ml}$ were prepared by further dilution of stock solution with the mobile phase (Kottu et al., 2012).

\section{Standard curve of Pioglitazone hydrochloride in methanol}

From the stock solution $1 \mathrm{ml}$ sample was pipette out in $10 \mathrm{ml}$ volumetric flask and diluted with methanol to give working standard solution containing pioglitazone hydrochloride in methanol at $100 \mu \mathrm{g} / \mathrm{ml}$. From this working standard solution appropriate dilutions were prepared to give 10, 20, 30, 40, 50, 60 $\mu \mathrm{g} / \mathrm{ml}$. All sample solutions were prepared in triplicate using stock and the absorbance checked by UV- Visible spectrophotometer (Shimadzu UV-1800) with quartz cells of $10 \mathrm{~mm}$ path length against the solvent methanol as a blank at $267.5 \mathrm{~nm}$ wavelength. The calibration curve was drawn by plotting the absorbances versus concentration.

\section{Standard curve of Pioglitazone $\mathrm{HCl}$ in $0.1 \mathrm{~N} \mathrm{HCl}$}

A $1 \mathrm{ml}$ sample was pipette out from the stock solution in $10 \mathrm{ml}$ volumetric flask and diluted with $0.1 \mathrm{~N} \mathrm{HCl}$ to give working standard solution containing pioglitazone hydrochloride in $0.1 \mathrm{~N}$ $\mathrm{HCl}$ at $100 \mu \mathrm{g} / \mathrm{ml}$. From this working standard solution appropriate dilutions were prepared to give $5,10,15,20,25,30,35,40,45$ $\mu \mathrm{g} / \mathrm{ml}$. All sample solutions were prepared in triplicate using stock and the absorbance checked by UV- Visible spectrophotometer (Shimadzu UV-1800) against the solvent $0.1 \mathrm{~N} \mathrm{HCl}$ as a blank at $269 \mathrm{~nm}$ wavelength. Then calibration curve was plotted.

\section{FTIR Spectroscopy analysis}

Fourier Transform Infrared Spectrophotometer (FTIR) is an important record which gives sufficient information of structure of compound. Infrared spectra of pure pioglitazone hydrochloride were determined on FTIR Spectrophotometer (FTIR 4100 JascoJapan) using $\mathrm{KBr}$ dispersion method. The base line correction was done using dried potassium bromide. Pioglitazone hydrochloride and $\mathrm{KBr}$ were previously dried in oven for $30 \mathrm{~min}$ and mixed thoroughly with potassium bromide in 1:300 (sample: $\mathrm{KBr}$ ) ratio in a glass mortar. These samples were then placed in a sample holder and scans were obtained at a resolution of $2 \mathrm{~cm}^{-1}$ from 4000 to $400 \mathrm{~cm}^{-1}$ 


\section{Differential scanning calorimetry (DSC) analysis}

Pure pioglitazone hydrochloride was analyzed for DSC analysis using differential scanning calorimeter. DSC measurements were performed on a differential scanning calorimeter equipped with an intra-cooler (DSC Mettler STAR SW 12.10, Switzerland). The analysis was carried out on $1 \mathrm{mg}$ sample sealed in standard aluminum pan. An empty aluminum pan was used as reference. Inert atmosphere was maintained by purging nitrogen gas at a flow rate of $25 \mathrm{ml} / \mathrm{min}$. at a scanning rate of $10^{\circ} \mathrm{C}$ per min from $40{ }^{\circ} \mathrm{C}$ to $240{ }^{\circ} \mathrm{C}$ (Nasr et al., 2008).

\section{Powder X-ray diffraction (PXRD) study}

$\mathrm{X}$-Ray diffraction measurements of pure pioglitazone hydrochloride were obtained by using Philips (PW3710) Expertpro MPD diffractometer (PAN analytical Inc, Germany) with resolution of $0.001 \mathrm{~A}^{\circ}$. The $10 \mathrm{mg}$ pure drug sample was sprinkled on vacuum grease applied glass slide to make a layer having a thickness of $\sim 0.5 \mathrm{~mm}$ and to slick the sample to slide before measurements. The samples were radiated using a copper target tube and exposed to all lines $(\lambda-1.54056)$. Scanning angles ranged from $5^{\circ}$ to $40^{\circ}$ of $2 \theta$. The current used was $30 \mathrm{~mA}$ and voltage of $40 \mathrm{kV}$. Diffraction pattern for pioglitazone hydrochloride were obtained (Satheeshbabu et al., 2012).

\section{Drug excipients compatibility study using FTIR}

The FTIR spectra of pioglitazone hydrochloride with excipients were recorded using Fourier Transform Infra-Red spectrophotometer (FTIR 4100 Jasco-Japan). The spectrum was scanned over a frequency range $4000-400 \mathrm{~cm}^{-1}$

\section{Selection of lipid, surfactants, drug: lipid ratio, aqueous phase} and stirring speed

Selection of lipid matrix is very important because it decides drug release and stability of liposphere formulation. Trial batches of pioglitazone hydrochloride liposphere formulations, different types of lipids were selected and lipospheres were prepared and characterized for their shape and size as shown in table 1 and table 2 (Nasr et al., 2008).

Surfactants selected on the basis of compatibility of surfactants with pioglitazone hydrochloride which gives stability to formulation. Trial batches of liposphere formulations were prepared by using P 90G, PVA and Poloxamer 188 as surfactant as shown in table 3. Prepared lipospheres were characterized for size and shape (Cortesi et al., 2002). Drug to lipid ratio is very important criteria for entrapment of drug in lipid matrix. Quantity of lipid was varied with constant amount of drug before proceeding to final optimization. These are depicted in table 4 (Nasr et al., 2008). Selection of aqueous phase volume for optimization of trial batches of liposphere formulations was varied from $10 \mathrm{ml}$ to $25 \mathrm{ml}$ and the variations obtained are reported in table 5. Stirring speed decides the particle size and entrapment efficiency of drug candidates as stirring speed is increased there is decrease in particle size but also decrease in entrapment efficiency. In trial batches of pioglitazone hydrochloride lipospheres stirring speed was varied at $7000 \mathrm{rpm}, 9000 \mathrm{rpm}, 12000 \mathrm{rpm}$ and at 15000 $\mathrm{rpm}$. and lipospheres were evaluated for entrapment efficiency and particle size (Cortesi et al., 2002).

Optimization of formulation of pioglitazone hydrochloride lipospheres $3^{2}$ full factorial design and ANOVA

Pioglitazone hydrochloride liposphere formulations were optimized by using $3^{2}$ full factorial design using Design Expert software (Version 8.0.4.1 Stat-Ease Inc., Minneapolis, USA). Parameters such as lipid concentration (Compritol ${ }^{\circledR} 888$ ATO) and surfactant concentration (P 90G: PVA: Poloxamer 188 in 1:2:1 ratio) were independent variables studied at three levels i.e. lipid quantity was evaluated at $60 \mathrm{mg}(-1$ level), $90 \mathrm{mg}(0$ level) and $120 \mathrm{mg}(+1$ level). Surfactant concentration was evaluated at 40 $\mathrm{mg}(-1$ level) $60 \mathrm{mg}(0$ level) and $80 \mathrm{mg}(+1$ level). Entrapment efficiency and particle size were response parameters or dependent variables. The data obtained for two responses were fitted using Design expert software 8.0.4 to linear model for pioglitazone hydrochloride lipospheres. Analysis of variance (ANOVA) was applied to estimate the significance of the model at the 5\% significance level (Shivakumaret al., 2007).

\section{Response surface analysis}

$3 \mathrm{D}$ response surface plots were plotted by using linear models were generated by regression analysis for pioglitazone hydrochloride liposphere. Effect of the lipid concentration and surfactants concentration on entrapment efficiency and particle size was checked.

\section{Evaluation of lipospheres batches Organoleptic Evaluations}

Pioglitazone $\mathrm{HCl}$ lipospheres batches were evaluated for organoleptic properties such as colour, odour and shape by visual observations.

\section{Determination of Entrapment Efficiency}

The entrapped drug concentration was determined by lysis of the lipospheres with chloroform. Accurately measured lipospheric dispersion $(10 \mathrm{ml})$ was centrifuged for $45 \mathrm{~min}$. Centrifuged dispersion was separated in two parts upper aqueous solution was removed and settled lipospheres were diluted in a mixture of $1 \mathrm{ml}$ chloroform and $9 \mathrm{ml}$ methanol. Above solution was sonicated (Biomedica, BMI-599) for 5 min to obtain a clear solution.

The concentration of pioglitazone hydrochloride in chloroform and methanol was determined by spectrophotometrically (Shimadzu, model UV-1800) at $267.5 \mathrm{~nm}$ after appropriate dilution. The entrapment efficiency was calculated through the following relationship (Elgart et al, 2012),

Entrapment efficiency (\%)

$=\frac{\text { Amount of drug in lipospheres }}{\text { Amount of drug incorporated in formulation }} \times 100$ 


\section{Determination of drug content}

The drug content was determined by breaking the upper lipid layer of lipospheres in chloroform. For each batch accurately weighed dried lipospheres $(10 \mathrm{mg})$ were diluted in solvent of $1 \mathrm{ml}$ chloroform and $9 \mathrm{ml}$ methanol. Obtained solution was sonicated (Biomedica, BMI-599) for 5 min to obtain a clear solution. Sediment was filtered by whatman filter paper 42 and used to analyze drug concentration of pioglitazone hydrochloride in methanol. After dilutions in methanol solution was scanned by spectrophotometrically (Shimadzu, model UV-1800) at wavelength of $267.5 \mathrm{~nm}$. The drug content was calculated through straight line equation (Brown et at., 2013).

\section{Differential scanning calorimetry}

A DSC measurement of formulation batch was performed as mentioned above in Differential scanning calorimetry (DSC) analysis.

\section{Powder X-ray diffraction (PXRD) study}

Powder X-ray diffraction (PXRD) study of formulation batch was performed as mentioned above in Powder X-ray diffraction (PXRD) study.

\section{Particle size analysis}

Analysis of the particle size distribution of prepared solid dry formulation of pioglitazone hydrochloride lipospheres was performed on motic digital microscope (Motic Inco Pvt. Ltd, B1223ASC). Solid dry liposphere formulations were diluted in distilled water in $10 \mathrm{mg}$ in $10 \mathrm{ml}$ and mounted on glass slide and analyzed for particle size at various objective lenses (Nasr et al., 2008).

\section{Surface morphology (SEM)}

The detailed surface characteristics of the optimized batch PLS 5 of pioglitazone hydrochloride lipospheres were observed by using a JEOL Scanning Electron Microscope (Model: JSM 5200, Japan).

The liposphere were attached to the specimen holder to aluminum stab by using a double coated adhesive tape and gold coater ( 20 nm thickness) under vacuum using a sputter coater (Model: IB-2, Hitachi, Tokyo, Japan). During gold coating process the samples were exposed to vacuum for 5-10 min. at $40 \mathrm{~mA}$ and investigate at accelerating voltage of $15 \mathrm{kV}$ and $10 \mathrm{kV}$ was applied and the image was photographed by Asia Pentex Camera (Elgart et al, 2012).

\section{In vitro drug release study and kinetics}

The drug release of pioglitazone hydrochloride from the lipospheres was studied using the USP Basket method by dissolution. Amount of lipospheres equivalent to $30 \mathrm{mg}$ of total pioglitazone hydrochloride was filled in a capsule. In vitro drug release was performed in acidic buffer $0.1 \mathrm{~N} \mathrm{HCl}(\mathrm{pH}-1.2)$ using USP type I basket dissolution apparatus maintained at $37^{\circ} \mathrm{C} \pm$ $0.5^{\circ} \mathrm{C}$, under stirring at $100 \mathrm{rpm}$. Samples were withdrawn periodically ( $0 \mathrm{~min}, 30 \mathrm{~min}, 1 \mathrm{hrs}$. up to $8 \mathrm{hr}$.) and the same volume was replaced immediately by fresh medium. Sample solutions were filtered, diluted appropriately and analyzed by measuring absorbance at $269 \mathrm{~nm}$ on UV- Visible spectrophotometer (Shimadzu UV-1800) (Avramoff et al., 2012).

\section{Selection of capsule}

Hard gelatin capsule was used for dissolution study of pioglitazone hydrochloride lipospheres. Capsules were selected on the basis of their size. Capsule used for dissolution study of the pioglitazone hydrochloride lipospheres were creamy white colored and size no. 3 which was sufficient for the filling of liposphere formulation in equivalent quantity of drug (Lachman and Lieberman, 2009).

\section{Stability testing of batches}

The stability study of liposphere optimized batch of pioglitazone hydrochloride loaded lipospheres (PLS 5) was carried out according to $\mathrm{ICH}$ and WHO guidelines. Optimized formulation was packed in aluminium foil and exposed this to different thermal conditions i.e., $5^{\circ} \mathrm{C} \pm 3^{\circ} \mathrm{C}, 25 \pm 2^{\circ} \mathrm{C} / 60 \pm 5 \% \mathrm{RH}$ and $40 \pm 2^{\circ} \mathrm{C} / 75$ $\pm 5 \% \mathrm{RH}$ for a period of two months and drug leakage behavior of formulation was tested by measuring the entrapment efficiency and particle size of lipospheres(WHO, 2009).

\section{RESULTS AND DISCUSSION}

\section{UV spectrum analysis of pioglitazone hydrochloride}

\section{Standard curve of Pioglitazone hydrochloride in methanol}

Standard calibration curve of pioglitazone hydrochloride in methanol at $267.5 \mathrm{~nm}$ was plotted as concentration versus absorbance. Beer-Lamberts law was obeyed through standard curves of pioglitazone hydrochloride solution in methanol which were linear in the 10 to $60 \mu \mathrm{g} / \mathrm{ml}$ concentration range tested as depicted in figure 1 and 0.9912 was found as coefficient of correlation.

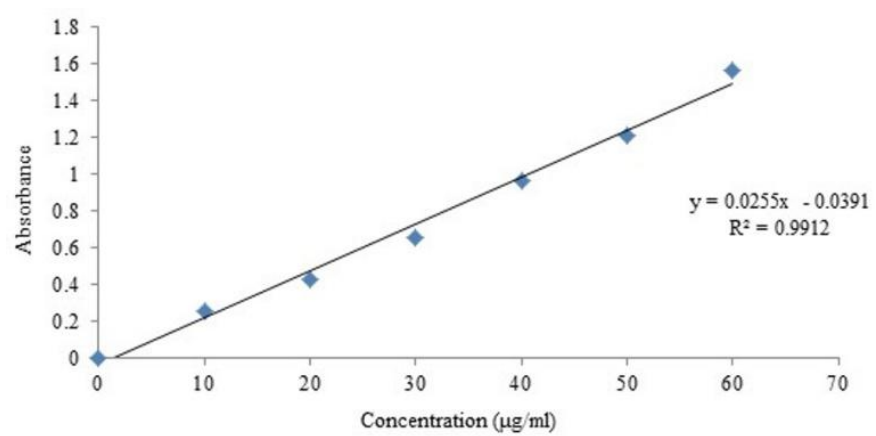

Fig. 1: Standard calibration curve of pioglitazone hydrochloride in methanol.

\section{Standard curve of Pioglitazone hydrochloride in $0.1 \mathrm{~N} \mathrm{HCl}$}

Standard calibration curve of pioglitazone hydrochloride in $0.1 \mathrm{~N} \mathrm{HCl}$ at $269 \mathrm{~nm}$ was plotted as concentration versus absorbance as shown in figure 2. It follows Beer-Lamberts law in a range of 5 to $45 \mu \mathrm{g} / \mathrm{ml}$ tested which were linear. Coefficient of correlation was found 0.9951 . 


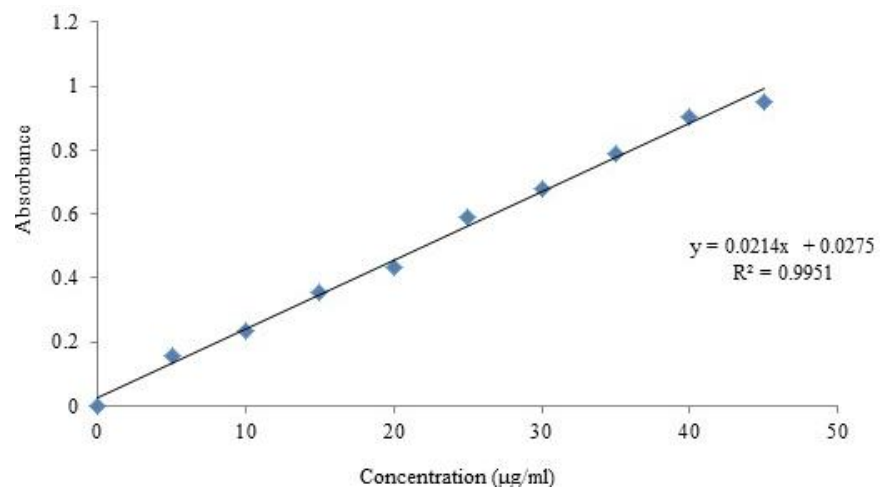

Fig. 2: Standard calibration curve of pioglitazone hydrochloride in $0.1 \mathrm{~N} \mathrm{HCl}$.

\section{FTIR Spectroscopy analysis}

FTIR spectra of pioglitazone hydrochloride revealed the presence of peaks at $1694 \mathrm{~cm}^{-1}$ due to $\mathrm{NH}-\mathrm{C}=\mathrm{O}$ group, peak 1617 $\mathrm{cm}^{-1}$ corresponds to the $\mathrm{S}=\mathrm{O}$, peak at $1460 \mathrm{~cm}^{-1}$ corresponds to the $\mathrm{C}-\mathrm{CH}_{3}$, and peak $1618 \mathrm{~cm}^{-1}$ corresponds to the $\mathrm{C}=\mathrm{C}$ group. Thus the FTIR spectrum confirms the identity of the pioglitazone hydrochloride which is depicted in figure 3.

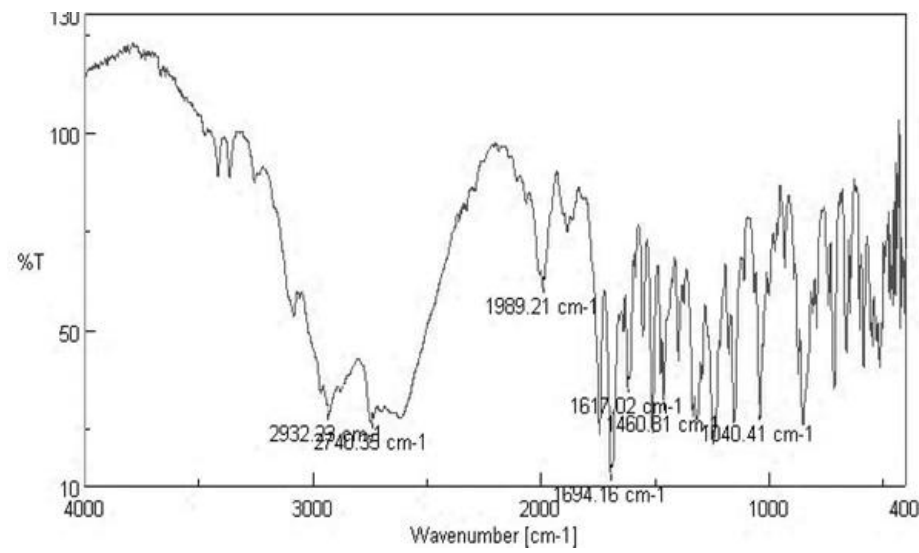

Fig.3: FTIR spectrum of pioglitazone hydrochloride.

\section{Differential scanning calorimetry (DSC) analysis}

DSC of Pioglitazone hydrochloride in figure 4 present endothermic peaks at $198.54^{\circ} \mathrm{C}$. The drug substances, whose melting curves are concave in shape, are characterized by the temperatures of their peak maxima.

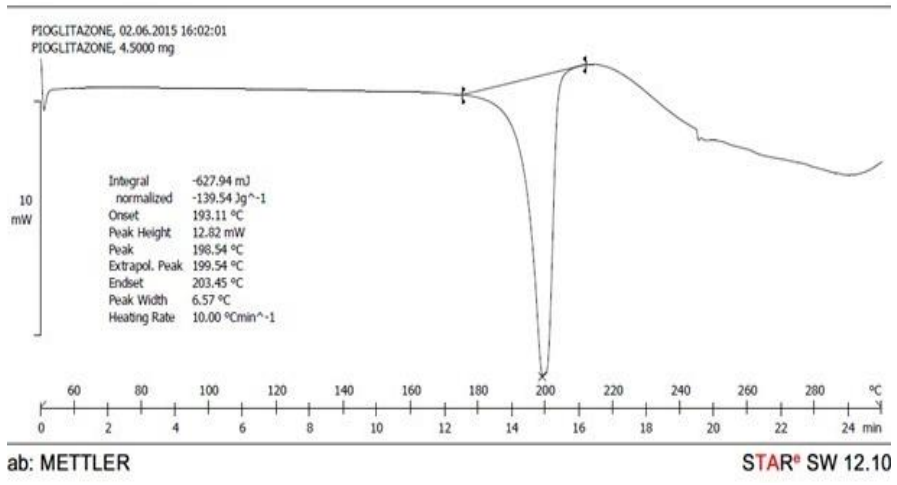

Fig. 4: DSC of pioglitazone hydrochloride.

\section{Powder X-ray diffraction (PXRD) study}

PXRD pattern of the dry powdered sample of drug and lipid were scanned by X-ray diffractometer. PXRD spectrum showed in figure 5 Compritol $^{\circledR} 888$ ATO shows numerous sharp peaks with high relative intensity at $2 \Theta$ values $21.51^{\circ}, 23.27^{\circ}$, $35.58^{\circ}$ and Pioglitazone hydrochloride pure drug showed peaks at $2 \Theta$ values $18.42^{\circ}, 19.28^{\circ}, 20^{\circ}, 23.89^{\circ}, 26.61^{\circ}$ (figure 6) representing the crystalline nature of lipid and also of drug.

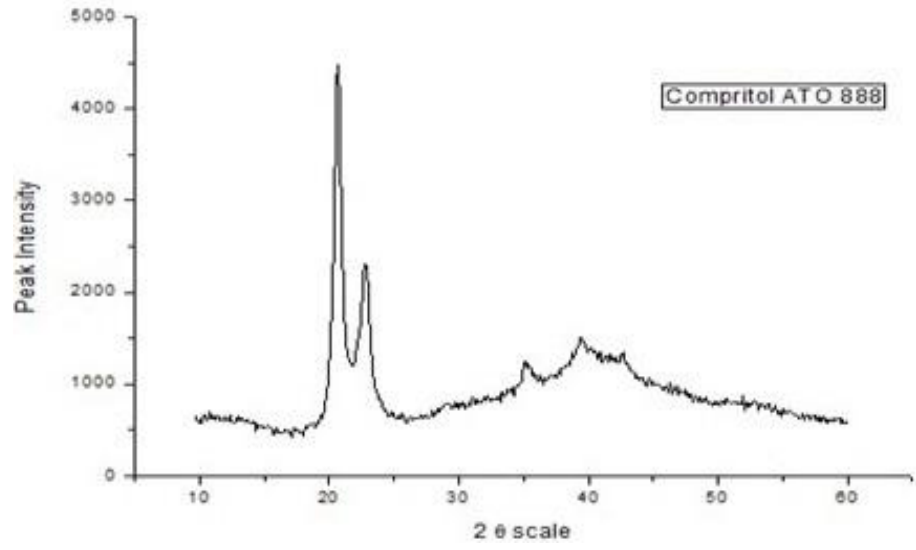

Fig. 5: PXRD spectra of Compritol® ATO 888 .

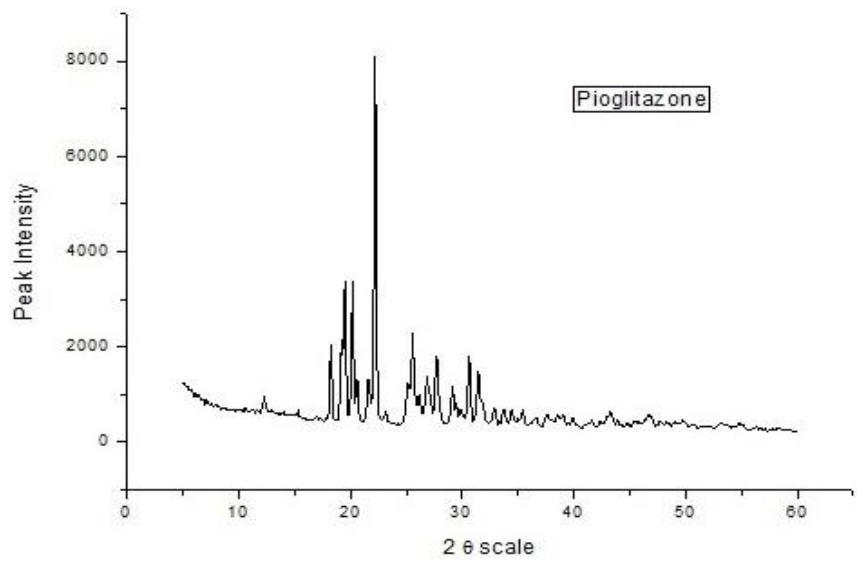

Fig. 6: PXRD spectra of Pure pioglitazone hydrochloride.

\section{Drug excipients compatibility study by using FTIR}

FTIR analysis of Pioglitazone hydrochloride and formulation excipients were carried out to identify potential interaction between drug and formulation excipients shown in figure 7. FTIR analysis of physical mixture containing Pioglitazone hydrochloride, Compritol $^{\circledR}$ ATO 888, Poloxamer 188 and PVA revels that there were no interactions between drug and formulation excipients as spectra showed all the characteristic peaks of pioglitazone hydrochloride.

\section{Selection of Lipid matrix}

From results depicted in table 1 and table 2, it was observed that lipospheres prepared with Compritol $^{\circledR} 888$ ATO were white, spherical shape and free flowing compared to lipospheres prepared with other lipids. 
Table 1: Trial batches for selection of lipid matrix.

\begin{tabular}{|c|c|c|c|c|c|c|c|c|c|c|c|}
\hline Batches & $\begin{array}{c}\text { Comp. } \\
888 \text { ATO } \\
(\mathrm{mg})\end{array}$ & $\begin{array}{c}\text { Precirol } \\
\text { ATO } 5(\mathrm{mg})\end{array}$ & $\begin{array}{l}\text { Bees } \\
\text { wax } \\
(\mathrm{mg})\end{array}$ & $\begin{array}{c}\text { Lanoline } \\
\text { (mg) }\end{array}$ & $\begin{array}{c}\text { Soya } \\
\text { lecithin } \\
\text { (ml) }\end{array}$ & $\begin{array}{l}\text { Carnauba } \\
\text { wax (mg) }\end{array}$ & $\begin{array}{l}\text { DW } \\
\text { (ml) }\end{array}$ & $\begin{array}{l}\text { Tween } \\
80(\mathrm{ml})\end{array}$ & $\begin{array}{c}\text { P 90G } \\
\text { (mg) }\end{array}$ & $\begin{array}{l}\text { PVA } \\
\text { (mg) }\end{array}$ & $\begin{array}{c}\text { Poloxam } \\
\text { er } 188 \\
(\mathrm{mg})\end{array}$ \\
\hline LS 1 & 30 & - & - & - & - & - & 20 & 1 & 10 & 5 & 10 \\
\hline LS 2 & 15 & 15 & - & - & - & - & 20 & 1 & 10 & 5 & 10 \\
\hline LS 3 & - & - & 30 & - & - & - & 20 & 1 & 10 & 5 & 10 \\
\hline LS 4 & - & - & - & - & 2 & - & 20 & 1 & 10 & 5 & 10 \\
\hline LS 5 & - & - & & - & - & 30 & 20 & 1 & 10 & 5 & 10 \\
\hline LS 6 & - & - & 15 & - & - & 15 & 20 & 1 & 10 & 5 & 10 \\
\hline LS 7 & - & - & - & 30 & - & - & 20 & 1 & 10 & 5 & 10 \\
\hline LS 8 & - & 30 & - & - & - & - & 20 & 1 & 10 & 5 & 10 \\
\hline LS 9 & 30 & - & - & - & 1 & - & 20 & 1 & 10 & 5 & 10 \\
\hline LS10 & 30 & - & 20 & - & - & - & 20 & 1 & 10 & 5 & 10 \\
\hline
\end{tabular}

Table 2: Observations of trial batches for selection of lipid matrix.

\begin{tabular}{|c|c|}
\hline Batch No. & Observations \\
\hline LS 1 & Spherical and free flowing lipospheres \\
\hline LS 2 & Slightly sticky and agglomerated particle size \\
\hline LS 3 & Slightly sticky and with large spherical shape particles \\
\hline LS 4 & Sticky, agglomerated and with no spherical shape \\
\hline LS 5 & Sticky and with no spherical shape \\
\hline LS 6 & Sticky, spherical particles \\
\hline LS 7 & Sticky, agglomerated and spherical shape \\
\hline LS 8 & Slightly sticky and Spherical particles \\
\hline LS 9 & Sticky, agglomerated and with no spherical shape \\
\hline LS 10 & Slightly sticky and spherical particles \\
\hline
\end{tabular}

Table 3: Trial batches for selection of surfactants.

\begin{tabular}{|c|c|c|c|c|c|c|c|c|}
\hline \multirow[b]{2}{*}{$\begin{array}{c}\text { Formulation } \\
\text { code }\end{array}$} & \multirow{2}{*}{$\begin{array}{c}\text { Lipid (mg) } \\
\text { Comp. } 888 \\
\text { ATO }\end{array}$} & \multirow{2}{*}{$\begin{array}{c}\text { Aqueous phase } \\
\text { Distilled water } \\
(\mathrm{ml})\end{array}$} & \multicolumn{4}{|c|}{ Surfactant } & \multirow[b]{2}{*}{$\begin{array}{l}\text { Speed } \\
(\text { rpm) }\end{array}$} & \multirow[b]{2}{*}{ Observations } \\
\hline & & & $\begin{array}{c}\text { P 90G } \\
\text { (mg) }\end{array}$ & $\begin{array}{l}\text { PVA } \\
\text { (mg) }\end{array}$ & $\begin{array}{c}\text { Poloxamer } \\
188 \text { (mg) } \\
\end{array}$ & $\begin{array}{l}\text { Tween } \\
80(\mathrm{ml})\end{array}$ & & \\
\hline LS 11 & 30 & 20 & 10 & 20 & 10 & 0.3 & 7000 & Aggregated irregular particles \\
\hline LS 12 & 30 & 20 & 10 & 20 & 10 & - & 7000 & Free flowing with improved particle size \\
\hline LS 13 & 30 & 20 & 10 & 5 & 5 & 0.3 & 7000 & Free flowing but not better particle size \\
\hline LS 14 & 30 & 20 & 10 & - & 10 & - & 7000 & Discrete spherical particles \\
\hline
\end{tabular}

Table 4: Pioglitazone trial batches for selection of Drug: Lipid ratio.

\begin{tabular}{|c|c|c|c|}
\hline Formulation code & $\begin{array}{c}\text { Pioglitazone hydrochloride (mg): } \text { Compritol }^{\circledR} 888 \\
\text { ATO (mg) }\end{array}$ & P 90G: PVA: Poloxamer 188 (1:2:1) (mg) & $\begin{array}{c}\text { Entrapment Efficiency } \\
(\%)\end{array}$ \\
\hline LS 15 & $30: 30$ & 40 & $42.09 \pm 0.77$ \\
\hline LS 16 & $30: 60$ & 40 & $79.73 \pm 1.24$ \\
\hline LS 17 & $30: 90$ & 40 & $77.90 \pm 1.36$ \\
\hline LS 18 & $30: 120$ & 40 & $65.35 \pm 0.97$ \\
\hline LS 19 & $30: 150$ & 40 & $70.32 \pm 1.78$ \\
\hline LS 20 & $30: 180$ & 40 & $77.64 \pm 0.91$ \\
\hline
\end{tabular}

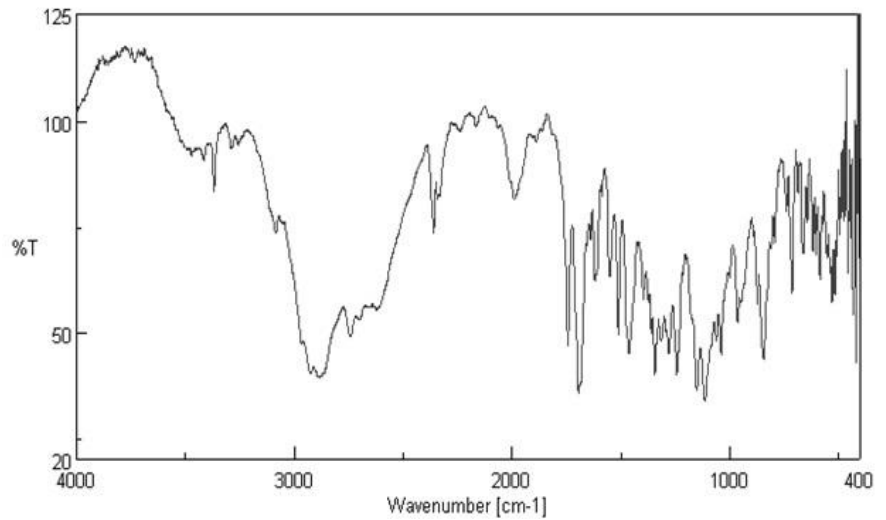

Fig. 7: FTIR spectra of physical mixture containing pioglitazone hydrochloride, Compritol ${ }^{\circledR}$ ATO 888, PVA and Poloxamer 188.

\section{Selection of Surfactants}

From the trial batches it was observed that lipospheres prepared with P 90G: PVA: Poloxamer 188 in (1:2:1) ratio with tween 80 were sticky, aggregated and with irregular shape whereas lipospheres prepared with P 90G: PVA: Poloxamer 188 in (1:0.5:0.5) ratio with tween 80 were free flowing but not better particle size. Lipospheres prepared with P 90G: Poloxamer 188 in (1:1) ratio was discrete spherical but not free flowing. For combination of surfactants such as P 90G: PVA: Poloxamer 188 in (1:2:1) ratio, it was observed that prepared lipospheres were free flowing, improved particle size than lipospheres prepared with other surfactants which are depicted in table 3.

\section{Selection of Drug: Lipid ratio}

This parameter was taken in consideration to know ability of lipid for entrapment of drug in lipospheres at constant drug and surfactant amount. From the results shown in table 4, it was observed that as the quantity of lipid at certain point shows increase in entrapment efficiency and below or above that ratio it shows decrease in entrapment efficiency. Entrapment efficiency was varied in the range of $42.09 \pm 0.37 \%$ for LS 15 batch to 79.73 
$\pm 0.32 \%$ for LS 16 batch. Formulation LS16, LS17, LS18 shows high entrapment efficiency than other batches.

\section{Selection of volume of aqueous phase}

Viscosity of dispersion was observed visually before air drying. The results obtained are shown in table 5 and from observations $20 \mathrm{ml}$ of aqueous phase volume selected for formulation of optimized lipospheres.

Table 5: Trial batches for selection of aqueous phase volume.

\begin{tabular}{ccl}
\hline $\begin{array}{c}\text { Formulation } \\
\text { code }\end{array}$ & $\begin{array}{c}\text { Volume of } \\
\text { aqueous phase } \\
(\mathbf{m l})\end{array}$ & \multicolumn{1}{c}{ Observations } \\
\hline LS 21 & 10 & Viscous dispersion of lipospheres \\
LS 22 & 15 & Viscous dispersion of lipospheres \\
LS 23 & 20 & Desired viscous dispersion of lipospheres \\
LS 24 & 25 & Less viscous dispersion of lipospheres \\
\hline
\end{tabular}

\section{Selection of stirring speed}

Lipospheres were prepared after variation in stirring speed. It was observed that as stirring speed was increased and the decrease in particle size as well as decrease in entrapment efficiency was observed. So the middle level speed i.e. $9000 \mathrm{rpm}$ was selected for preparation of optimized formulation.

\section{Optimization for formulation of pioglitazone hydrochloride lipospheres}

\section{$3^{2}$ full factorial design and ANOVA}

$3^{2}$ full factorial design was applied to optimize the batch of pioglitazone hydrochloride lipospheres as shown in table 6 . Among several compositions, PLS 5 was found to be optimized formulation having entrapment efficiency $79.69 \pm 1.35 \%$ as depicted in figure 10 and particle size $23.74 \pm 0.35 \mu \mathrm{m}$ as presented in figure 14 . The linear models generated by the design are given below. The final equations obtained in terms of coded factors for PLS 5 represented as follows:

Entrapment efficiency... $\mathrm{Y}_{1}=+83.14+6.70 \mathrm{X}_{1}+3.64 \mathrm{X}_{2}-4.00$ $\mathrm{X}_{1} \mathrm{X}_{2}-1.86 \mathrm{X}_{1}^{2}-8.56 \mathrm{X}_{2}^{2}$

Particle size..... $Y_{2}=+21.77-0.22 X_{1}-3.54 X_{2}$

Using ANOVA results linear model were generated for percent entrapment efficiency was found to be significant. With an $F$-value of 9.06 and $\mathrm{P}$ Value (Prob> F) is 0.0496 and equation represented as $\mathrm{Y}_{1}$. Linear model for particle size was also developed and represented as equation $\mathrm{Y}_{2}$ with an $F$-value of 5.16 and $\mathrm{P}$ Value (Prob> F) is 0.0497 which is also linear (Fang and Hung, 2007).

\section{Response surface analysis}

Response surface analysis was checked by plotting 3D response plots by linear models generated by regression analysis. Response parameter Y was represented by a curvature surface as a function of $\mathrm{X}$ for PLS 5. Effect of the concentration of lipid surfactants on entrapment efficiency and particle size was proof from the 3D response surface plot for PLS 5. This is represented in figure 8 . From the $3 \mathrm{D}$ plots it was observed that the entrapment efficiency and particle size values were affected more by the levels of lipid and surfactants.

Table 6: Formulation composition of pioglitazone hydrochloride lipospheres from randomized runs in $3^{2}$ full factorial design.

\begin{tabular}{|c|c|c|c|c|c|c|c|c|}
\hline \multirow[b]{2}{*}{ 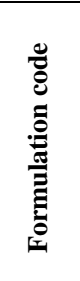 } & \multirow[b]{2}{*}{ 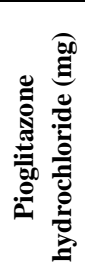 } & \multirow[b]{2}{*}{ 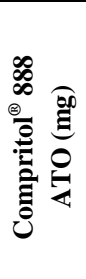 } & \multicolumn{4}{|c|}{ Surfactants (mg) } & \multirow[b]{2}{*}{ 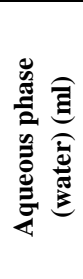 } & \multirow{2}{*}{ 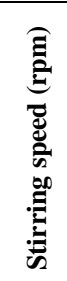 } \\
\hline & & & $\begin{array}{l}\text { b } \\
\stackrel{a}{a} \\
0\end{array}$ & 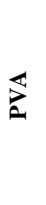 & 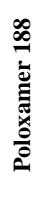 & 吾 & & \\
\hline PLS 1 & 30 & 60 & 10 & 20 & 10 & 40 & 20 & 9000 \\
\hline PLS 2 & 30 & 60 & 15 & 30 & 15 & 60 & 20 & 9000 \\
\hline PLS 3 & 30 & 60 & 20 & 40 & 20 & 80 & 20 & 9000 \\
\hline PLS 4 & 30 & 90 & 10 & 20 & 10 & 40 & 20 & 9000 \\
\hline PLS 5 & 30 & 90 & 15 & 30 & 15 & 60 & 20 & 9000 \\
\hline PLS 6 & 30 & 90 & 20 & 40 & 20 & 80 & 20 & 9000 \\
\hline PLS 7 & 30 & 120 & 10 & 20 & 10 & 40 & 20 & 9000 \\
\hline PLS 8 & 30 & 120 & 15 & 30 & 15 & 60 & 20 & 9000 \\
\hline PLS 9 & 30 & 120 & 20 & 40 & 20 & 80 & 20 & 9000 \\
\hline
\end{tabular}

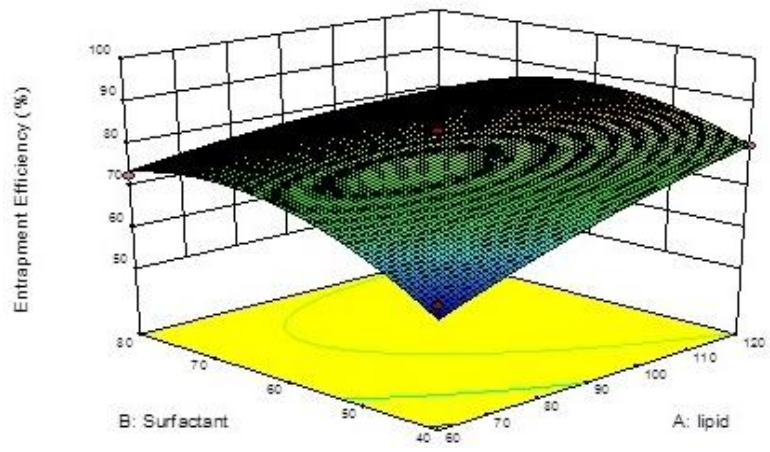

Fig. 8: Response surface plots of Pioglitazone hydrochloride Lipospheres for parameter entrapment efficiency.

\section{Evaluation of Liposphere batches}

\section{Organoleptic Evaluations}

Organoleptic properties of the formulation batches of pioglitazone hydrochloride lipospheres (PLS 1- PLS 9) were evaluated for colour, odour and shape. All batches were of offwhite color and faint odour with spherical shaped free flowing lipospheric particles.

\section{Determination of entrapment efficiency}

Lipospheres are formulated to deliver the intact drug at targeted tissue. Lipospheres have ability to entrap lipophilic drug in high amount. Entrapment efficiency of pioglitazone hydrochloride lipospheres was evaluated and from the results it was observed that the highest entrapment efficiency was observed for PLS 7, PLS 3 and PLS 5 as $91.64 \pm 2.20 \%, 83.14 \pm 1.65 \%$ and $79.69 \pm 1.35 \%$ respectively. 
As indicated in figure 10 , entrapment efficiency of pioglitazone hydrochloride lipospheres ranged from $58.62 \pm 0.68 \%$ for PLS 9 batch to $91.64 \pm 2.20 \%$ for PLS 7 batch was achieved. Entrapment efficiency was mainly affected by the composition and amount of lipid used. Melt dispersion technique used to formulate lipospheres was best suited and resulted into high entrapment. High entrapment for the pioglitazone hydrochloride is due to lipophilic nature of drug which was easily dispersed in molten compritol $^{\circledR} 888$ ATO before emulsification. Surfactants used in pioglitazone hydrochloride lipospheres provide stability to lipid structure and ultimately for high entrapment of drug in lipospheres.

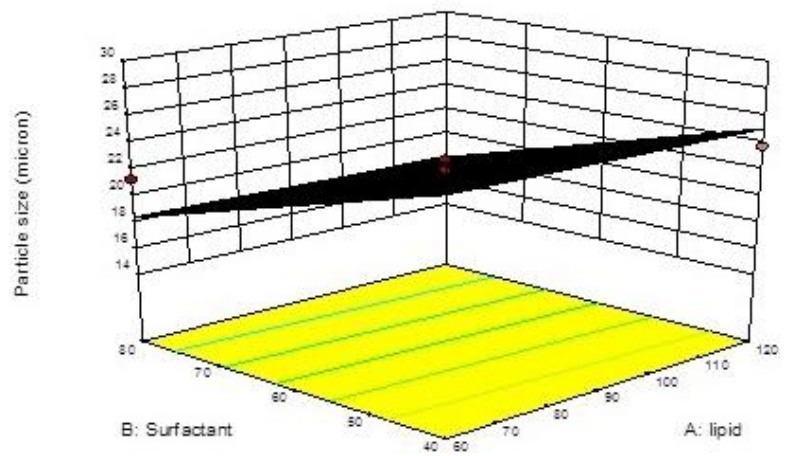

Fig. 9: Response surface plots of Pioglitazone hydrochloride Lipospheres for parameter particle size.

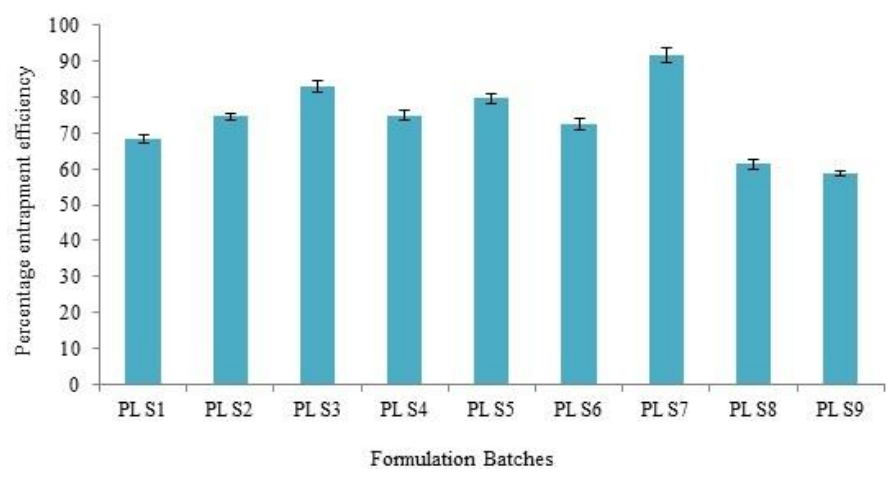

Fig. 10: Graphical representation of observed responses of pioglitazone hydrochloride lipospheres for percentage entrapment efficiency.

\section{Determination of percentage drug content}

The percentage drug content of lipospheres was depends on the ability of lipid to entrap drug, surfactants used and method of preparation. Drug content of dry solid pioglitazone hydrochloride liposphere batches were determined and from observed results drug content varied in the range of $79.53 \pm 1.52 \%$ for PLS 7 batch to $94.63 \pm 2.10 \%$ for PLS 5 batch. The highest drug content was observed for PLS 5 batch as $94.63 \pm 2.10 \%$. This is shown in figure 11. Melt dispersion technique has given high drug content. Drug content was also affected by stirring speed. With increase in stirring speed, decrease in particle size and drug content were observed. For formulation of pioglitazone hydrochloride lipospheres stirring speed was selected as $9000 \mathrm{rpm}$ after preparation of various trial batches.

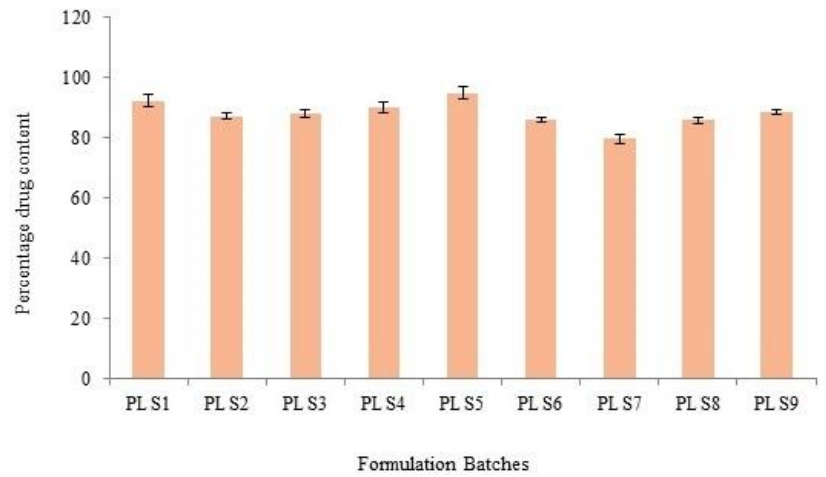

Fig. 11: Graphical representation of observed responses of optimized batches of dry solid pioglitazone hydrochloride lipospheres for percentage drug content.

\section{Differential Scanning Calorimetry}

Differential scanning calorimetry characterizes the nature of liposphere formulation. Pure pioglitazone hydrochloride and optimized batch PLS 5 were analyzed using DSC. The main purpose of DSC study is to obtain melting point of particles. DSC thermograms of pure pioglitazone hydrochloride and PLS 5 batch overlay is shown in figure 12 .

DSC thermograms of pure pioglitazone hydrochloride showed endothermic peaks at $198.54^{\circ} \mathrm{C}$ which is melting point of the drug. PLS 5 optimized formulation showed an endothermic peak at $73.5^{\circ} \mathrm{C}$ which is close to the melting point of lipid compritol $^{\circledR} 888$ ATO as in formulation of pioglitazone hydrochloride lipospheres compritol ${ }^{\circledR} 888$ ATO is main lipid which forms the outer coat of lipospheres and gives stability to drug. Disappearance of the drug peaks suggests entrapment of pioglitazone hydrochloride in the lipid matrix because when drug is in free form in formulation then DSC thermogram of optimized batch gives peaks near to that of pure drug.

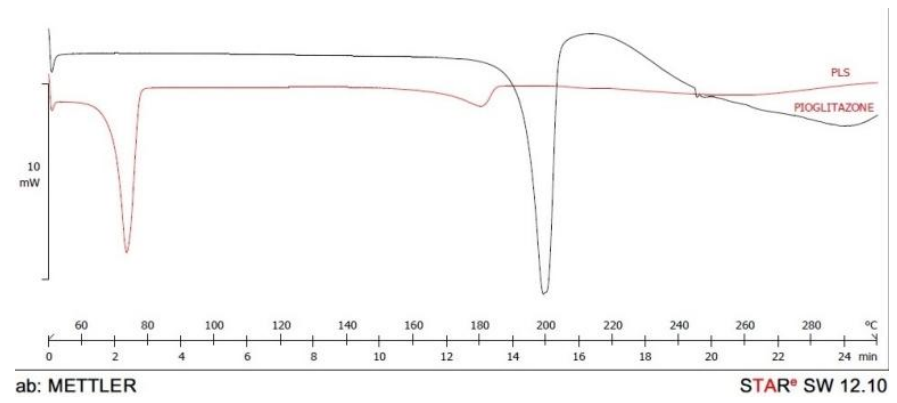

Fig. 12: DSC thermogram of pure pioglitazone hydrochloride and pioglitazone hydrochloride loaded optimized batch (PLS 5): overlay.

\section{X-ray diffraction studies}

The powder X-ray diffraction spectra of optimized batch PLS 5 were noted. The PXRD spectra in the figure 13 indicates diffraction peaks of pioglitazone hydrochloride formulation PLS 5 batch at $2 \theta$ values of $18.16^{\circ}, 20.84^{\circ}, 22.89^{\circ}, 30.61^{\circ}$ were observed in lipospheres these peaks are near to pure pioglitazone hydrochloride diffraction peaks shown in figure 6. It clearly indicates formulation of pioglitazone hydrochloride batch PLS 5 is crystalline in nature. 


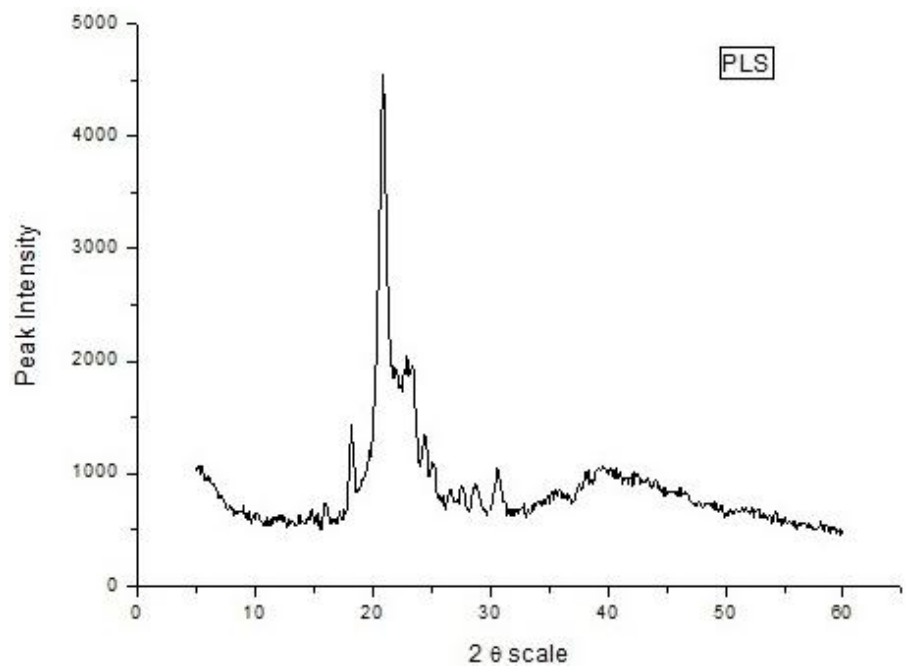

Fig. 13: Powder X-ray diffraction spectra of PLS 5 batch.

\section{Particle size distribution}

Particle size distribution is important characteristic for liposphere formulation as particle size is too small there is low entrapment of drug. When loading of drug is high then particles are also in larger size. Particle size is mainly affected by the stirring speed and volume of aqueous phase.

The optimized formulations of solid pioglitazone hydrochloride lipospheres was evaluated for particle size by using motic digital microscope (Motic Inco Pvt. Ltd, B1- 223ASC) which showed size distribution in the range of $15.64 \pm 0.21 \mu \mathrm{m}$ for PLS 4 batch to $28.3 \pm 0.25 \mu \mathrm{m}$ for PLS 9 batch. Mainly particle size varies with aqueous phase volume and stirring speed as $20 \mathrm{ml}$ aqueous phase and $9000 \mathrm{rpm}$ stirring speed gives better particle size and good entrapment efficiency for pioglitazone hydrochloride lipospheres. The average particle size of PLS 5 optimized batch was found to be $23.74 \pm 0.35 \mu \mathrm{m}$ which is presented in figure 14.

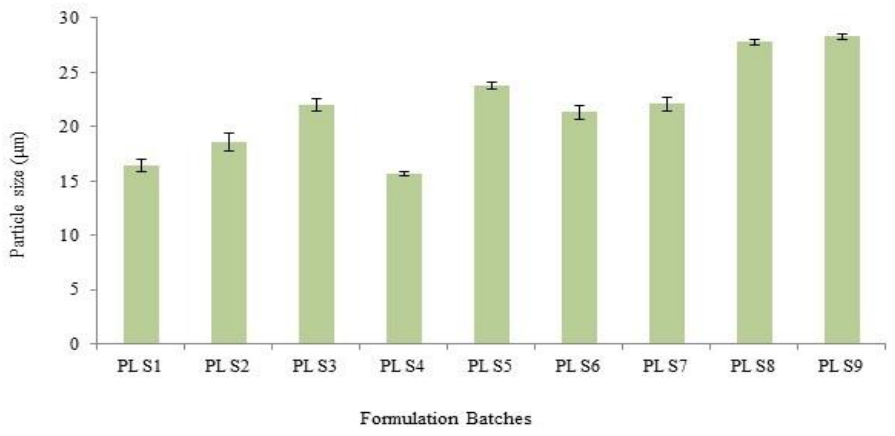

Fig. 14: Particle size distribution of solid pioglitazone hydrochloride lipospheres factorial batches.

\section{SEM studies for surface morphology}

The surface morphology gives the evidences of structure and shape of lipospheres. Optimized dry batch PLS 5 of pioglitazone hydrochloride lipospheres recorded with a JEOL Scanning Electron Microscope (JSM 5200, Japan). SEM studies revealed formation of nearly spherical shape with smooth surfaced particles for dry solid pioglitazone hydrochloride lipospheres shown in figure 15. Spherical shape of lipospheres is due to intact structure of lipospheres. It clearly indicates entrapment of drug in spherical shaped lipospheres. Numerous drug crystals were seen in high magnification which indicates high entrapment of drug in lipospheres. This observation obtained in good agreement with the observation of particle size by optical microscopy using motic digital microscope (Motic Inco Pvt. Ltd, B1- 223ASC).

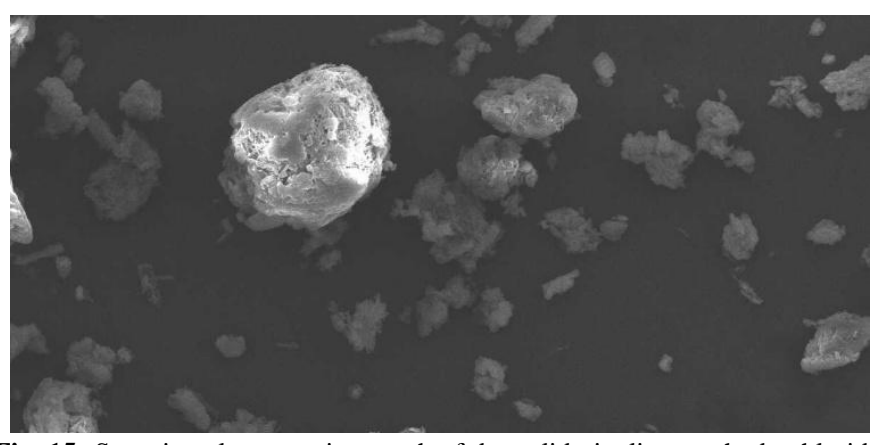

Fig. 15: Scanning electron micrograph of dry solid pioglitazone hydrochloride formulation (PLS 5).

\section{In vitro drug release study of pioglitazone hydrochloride lipospheres}

The in vitro drug release profiles of pioglitazone hydrochloride lipospheres were done using USP type I basket dissolution apparatus. Dissolution is a process in which a solid substance solubilizes in a given solvents i.e., mass transfer from solid phase to the liquid phase. Dissolution study of pioglitazone hydrochloride lipospheres was carried out by adding lipospheres equivalent to $30 \mathrm{mg}$ of total pioglitazone hydrochloride drug in unit dosage form as capsule. All of the drug release could last to 8 hrs. As showed in figure 16, drug release of pioglitazone hydrochloride lipospheres varied in the range of $73.47 \pm 2.33 \%$ for PLS 6 batch to $103.82 \pm 3.40 \%$ for PLS batch 1 . All the batches showed a sustained drug release profile and showed higher drug release for PLS batch 1 were $103.82 \pm 3.40 \%$ and PLS batch 5 were $96.06 \pm 1.85 \%$.

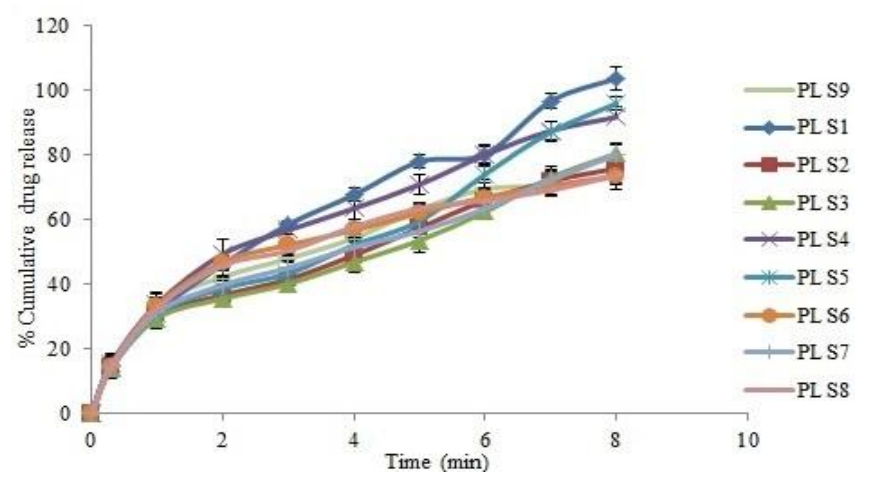

Fig. 16: Percent cumulative drug release of pioglitazone hydrochloride lipospheres (PLS 1 - PLS 9).

\section{Drug release kinetics (Best fit model)}

Drug release mechanisms and kinetics are two important characteristics of a delivery system in describing the drug 
dissolution profile where $\mathrm{f}$ test is a function of time related to the amount of drug dissolved from the pharmaceutical dosage form. Several mathematical and kinetic models describe the dissolution of drug from immediate release and modified release dosage forms. Drug dissolution from solid dosage forms has been described by kinetic models in which the dissolved amount of drug (Q) is a function of the test time, $\mathrm{t}$ or $\mathrm{Q}(\mathrm{t})$ (Brahmankar and Jaiswal, 1995). The data obtained after the dissolution testing optimized batch was subjected to various kinetic models and the best fit model was predicted for pioglitazone hydrochloride lipospheres PLS batch 5. Coefficient of correlation $\left(\mathrm{R}^{2}\right)$ value of PLS 5 batch is 0.942 and $n$ value is 0.384 . It is clear that PLS 5 batch follows Quasi-Fickian type of transport and KorsmeyerPeppas model is best suited for this formulation as the value of $\mathrm{n}$ is 0.384 is $<0.5$.

\section{Stability testing of batches}

The stability study of pioglitazone hydrochloride loaded lipospheres optimized PLS batch 5 was carried out according to ICH and WHO guidelines. Optimized formulation was packed in aluminium foil and exposing this to different thermal conditions. Entrapment efficiency of pioglitazone hydrochloride lipospheres PLS 5 batch was $78.28 \pm 0.86 \%$ and Particle size was $24.16 \pm$ $0.94 \mu \mathrm{m}$. provided best results as shown in table 7 .

Table 7: Stability studies of optimized formulations of pioglitazone hydrochloride (PLS 5) lipospheres.

\begin{tabular}{ccc}
\hline \multirow{2}{*}{ Conditions } & \multicolumn{2}{c}{ Pioglitazone hydrochloride (PLS 5) } \\
\cline { 2 - 3 } & $\begin{array}{c}\text { Entrapment } \\
\text { Efficiency }(\%)\end{array}$ & Particle Size $(\boldsymbol{\mu m})$ \\
\hline Initial & $79.69 \pm 1.16$ & $23.74 \pm 0.35$ \\
\hline & 1 month & $23.85 \pm 0.44$ \\
\hline $5^{\circ} \mathrm{C} \pm 3^{\circ} \mathrm{C}$ & $79.44 \pm 1.35$ & $24.30 \pm 0.06$ \\
$25 \pm 2^{\circ} \mathrm{C} / 60 \pm 5 \% \mathrm{RH}$ & $79.52 \pm 1.82$ & $24.53 \pm 0.42$ \\
$40 \pm 2^{\circ} \mathrm{C} / 75 \pm 5 \% \mathrm{RH}$ & $78.73 \pm 1.28$ & $24.16 \pm 0.94$ \\
\hline & 2 months & $25.61 \pm 0.92$ \\
\hline $5^{\circ} \mathrm{C} \pm 3{ }^{\circ} \mathrm{C}$ & $78.28 \pm 0.86$ & $25.47 \pm 0.36$ \\
$25 \pm 2^{\circ} \mathrm{C} / 60 \pm 5 \% \mathrm{RH}$ & $78.17 \pm 1.75$ & \\
$40 \pm 2^{\circ} \mathrm{C} / 75 \pm 5 \% \mathrm{RH}$ & $77.7 \pm 0.87$ & \\
\hline
\end{tabular}

\section{CONCLUSION}

Lipospheres can be considered as a promising drug delivery for anti-diabetic drug like pioglitazone hydrochloride. Lipospheres of pioglitazone hydrochloride were developed successfully by melt dispersion technique which is rapid, simple, reproducible and inexpensive technique. Scanning electron microscopy results indicates nearly spherical sized smooth surfaced lipospheres. In vitro drug release study proved that the liposphere formulation of pioglitazone hydrochloride lipospheres could release maximum drug around 8 hrs. In vitro drug release study proves that the liposphere formulation of pioglitazone hydrochloride was able to sustain the drug release. Accelerated stability study of optimized batch of pioglitazone hydrochloride lipospheres PLS 5 for two months revealed that the formulation was stable at $5^{\circ} \mathrm{C} \pm 3^{\circ} \mathrm{C}$.

\section{ACKNOWLEDGEMENT}

The authors are thankful to SAVA Healthcare Ltd., India for providing gift sample of pioglitazone hydrochloride.

\section{CONFLICT OF INTEREST}

The authors declare that they have no conflict of interest.

\section{REFERENCES}

Avramoff A, Khan W, Ezra A, Elgart A, Hoffman A, Domb AJ. Cyclosporin pro-dispersion liposphere formulation. J Controlled Release, 2012; 30: 1-6.

Brahmankar DM, Jaiswal SB. 1995. Biopharmaceutics and Pharmacokinetics- A Treatise, New Gyan offset printers, Delhi, India: Vallabh Prakashan.

Brown SA, Chime SA, Attama AA, Agu CI, Onunkwo GC. In vitro and In vivo Characterisation of Piroxicam-Loaded Dika Wax Lipospheres. Trop J Pharm Res, 2013; 12(1): 33-38.

Chime SA, Onyishi IV. Lipid-based drug delivery systems (LDDS): Recent advances and applications of lipids in drug delivery. Afr J Pharm Pharmacol, 2013; 7(48): 3034-3059.

Chime SA, Kenechukwu FC, Onunkwo GC, Attama AA, Ogbonna JD. Recent Advances in Lipospheres Drug Delivery System. Journal of Pharmacy Research, 2012; 5(3): 1743-1748.

Cortesi R, Esposito E, Luca G, Nastruzzi C. Production of lipospheres as carriers for bioactive compounds. Biomaterials, 2002; 23: 2283-2294.

Elgart A, Cherniakov I, Aldouby Y, Domb AJ, Hoffman A. Lipospheres and pro-nano lipospheres for delivery of poorly water soluble compounds. ChemPhys of Lipids, 2012; 165: 438- 453.

Fang JY, Hung CF. A study of the formulation design of acoustically active lipospheres as carriers for drug delivery. Eur J Pharm Biopharm, 2007; 67: 67-75.

ICMR. 2005. Guidelines for Management of Type 2 Diabetes, Pharmacological treatment for diabetes; Section- 7: 16-31.

Indian Pharmacopoeia. 2010. Government of India, Ministry of Health and Family Welfare, Published by The Indian Pharmacopoeia Commission, Ghaziabad. $6^{\text {th }}$ edition, Volume 1-3: 1418-1420, 1916-1918.

Kottu PK, Gadad AP, Dandagi PM. Method Development and Validation for the Simultaneous estimation of Pioglitazone and Glimepiride- A UV Spectrophotometric Approach. Indian Drugs, 2012; 49(11): 30-35.

Lachman L, Lieberman HA.Special Indian edition 2009.The Theory and Practice of Industrial Pharmacy. New Delhi, India: CBS Publishers and Distributors.

Lakshmi PK, Saroja Ch. Lipospheres: Recent Advance in Lipid Drug Delivery. Journal of Pharmacy Research, 2012; 5(4): 2094-2100.

Momoh MA, Esimone CO. Phospholipon 90H (P90H)-based PEGylated microscopic lipospheres delivery system for Gentamicin: an antibiotic evaluation. Asian Pac J Trop Biomed, 2012; 2(11): 889-894.

Nasr M, Mansour S, Mortada ND, Shamy AE. Lipospheres as Carriers for Topical Delivery of Aceclofenac: Preparation, Characterization and In Vivo Evaluation. AAPS PharmSciTech, 2008; 9(1): 154-162.

Patel M, Patel S, Patel N. A Review: Novel oral lipid based formulation for poorly soluble drugs. International Journal of Pharmaceutical Sciences and Nanotechnology, 2011; 3(4): 1182-1192.

Satheeshbabu N, Prabhakaran L, Gayatri R, Arun GK, Sundareswara KC, Arthi I.Design and Development of Lipospheres for Controlled Delivery for Antimalarial Drugs. Int J Pharm PharmSci, 2012; 4(4): 87-92.

Satheeshbabu N, Gowthamrajan K. Manufacturing techniques of Lipospheres: Overview. Int J Pharm PharmSci, 2011; 3(4): 17-21. 
Shivakumar HN, Patel PB, Desai BG, Ashok P, Arulmozhi S. Design and statistical optimization of Glipizide loaded lipospheres using response surface methodology. Acta Pharm, 2007; 57: 269-285.

Soumya S, Doney AB, Sabitha M. Current trends in lipid based delivery systems and its applications in drug delivery. Asian J Pharm Clin Res, 2012; 5(3): 4-9.

U.S. Department of Health and Human Services. Food and Drug Administration Center for Drug Evaluation and Research (CDER), February 2008. Guidance for Industry, Diabetes Mellitus: Developing Drugs and Therapeutic Biologics for Treatment and Prevention.1-30.

World Health Organization.2009. Stability testing of active pharmaceutical ingredients and finished pharmaceutical products. WHO Technical Report Series, No. 953; 87-130.

\section{How to cite this article:}

Bhosale UM, Galgatte UC, Chaudhari PD. Development of pioglitazone hydrochloride lipospheres by melt dispersion technique: Optimization and evaluation. J App Pharm Sci, 2016; 6 (01): 107-117. 